DOI: $10.24193 /$ tras.64E.3

Published First Online: 10/28/2021

\section{MANAGER'S ROLE AND \\ PERFORMANCE INFORMATION USE: \\ EVIDENCE FROM US FEDERAL AGENCIES}

\author{
Eunjin HWANG
}

\section{Eunjin HWANG}

Visiting Fellow, Korea Institute of Public Administration (KIPA), Seoul, South Korea

E-mail: eunjin.hwang0405@gmail.com

\section{Abstract}

This article explores the relationship between performance information use for different functions based on two of Moynihan's analyses and a managerial perspective, utilizing passive and purposeful use. The results of this study suggest that both accountability and managers' proximity to the performance system exert strong influence on the use of performance information in the public sector. In terms of organizational factors, data quality and meaningful measures are associated with performance information use. On the other hand, external attention has no effect on performance information use regardless of the types of performance information.

Keywords: performance information, manager's involvement, manager's awareness, accountability. 


\section{Introduction}

Numerous significant efforts have been made to increase performance in the public sector in the U.S. government. The Bush administration established the PART (Program Assessment Rating Tool) to encourage performance information use by focusing on program-level measures (Moynihan and Lavertu, 2012). The Obama administration also focused on performance information use by enacting the GPRA (Government Performance and Results Act) Modernization Act of 2010, which focused on cross-agency and agency-level priority goals. This legislation also entails active performance management by linking between goal setting and performance information (GAO, 2011). These efforts, however, have not affected active performance information use among managers, according to the 2014 study conducted by the General Accounting Office (GAO, 2014).

In addition, to increase performance, studies have traditionally focused on performance measurement and management foci in the wake of new public management reforms. Measurement involves numbers, including non-numerical outputs, outcomes, and throughputs of organizations, and thus it can create performance information based on these output and outcome measures. On the other hand, lately, the topic of 'performance information use' has attracted scholarly attention. According to these studies, performance information has several advantages. Citizens can judge using performance information whether governments perform well or poorly by observing how their taxes are utilized for the public, thereby increasing transparency (Talbot, 2005). Managers use performance information as a device to control their service delivery departments and to communicate with monitoring groups, such as Office of Management and Budget (OMB) and Congress (Askim, 2009). Congress can also use such information to evaluate whether managers and agencies perform well or poorly from an efficiency perspective, focusing on input-output relations (Behn, 2003; Talbot, 2005).

Moynihan and Pandey (2010) raised a significant question in their article: why do managers use performance information in response to external attention, such as from the OMB, Congress, and audits? Moynihan and Lavertu (2012) have confirmed that a manager's PART and GPRA routines, leadership commitments, and discretion all play key roles in information use. Based on their findings, our understanding of managerial information use should be updated. A manager's involvement and perception of performance related activities need further specification to increase performance information use. Their study was conducted with 2000 and 2007 data, with their earlier data published before GPRAMA (GPRA Modernization Act) was enacted. GPRAMA, enacted in 2010, provides important tools to help overcome the challenges of performance information use in their agency performance plan. Thus, the earlier data was also of limited use in studying the relationship between managerial influences and performance information.

Therefore, this study uses the updated survey collected by the GAO in 2013 and 2017 for investigating federal performance management practices. This paper follows Moynihan and Lavertu's (2012) study focusing on management perspectives. This 
study includes four sections functioning as follows: (1) to determine the influence of these variables on performance information use based on Moynihan's categories, passive use and purposeful use; (2) to identify the relationship between independent variables - a manager's proximity to the performance system, accountability, and organizational behavior factors - and the dependent variable, performance information use; (3) to employ Moynihan's model using more sophisticated statistical methods to analyze the data; and (4) to discuss the results and provide direction for future studies.

\section{Performance information use}

Performance information refers to the process of collecting and reporting performance data for effective monitoring and program management (Pollanen, 2014). Performance information includes the performance of an organization in relation to certain goals, and this can be understood as resources that have been purchased, including outputs, outcomes, efficiency, and effectiveness (Moynihan and Lavertu, 2012). A variety of studies have emphasized the various effects of using performance information (Moynihan et al., 2012). Performance information can function as an interactive dialogue between interests (Moynihan, 2008) in which the actors contribute their perspectives through their decision making. Their participation is necessary because decision makers are not always consistently rational, and some decisions are deemed political. Performance data also improves organizational capacity when organizations are in a process of innovation because agency actors can engage in learning, as well as accumulate professionalism and specializations in particular functions by developing performance information systems. Furthermore, performance information use protects organizations from criticism and maintains resources, since performance use as a tool can be used in communication with external stakeholders (Stewart, 1984; Mayne, 1997).

Moynihan (2009) outlines the 'Four P's': Passive, Political, Perverse, and Purposeful. According to his definition, passive use focuses on complying with requirements for increased performance, while political use employs decision-making to receive more support from stakeholders. Perverse use refers to unintended information collected for personal gain, and purposeful use refers to a desired behavior. Among these four P's, this study focuses on passive and purposeful use. Passive use simply involves complying with government policies to report performance information. On the other hand, purposeful use has received attention in performance studies (Kroll, 2015). Kroll and Vogel (2014) define purposeful use as 'the making of better-informed management decisions based on performance data' (p. 976). It entails 'using performance information to improve services through better-informed decisions, goal-based learning, or sanctioning and rewarding' (Kroll, 2015, pp. 461-462).

Only two of Moynihan's four Ps are found in the GAO survey data, and due to its reliance on this secondary data, the present study employs purposeful and passive use as sufficient categories to account for the performance use reflected in the data. 
It examines how managerial involvement in GPRA processes and PART reviews relates to performance information use, focusing on passive and purposeful forms of performance information use with data from 2000 and 2007. Managers adopt passive approaches when they comply with norms to meet the requirements of performance systems (Radin, 2006; Moynihan and Lavertu, 2012), while managers adopt purposeful forms of performance information use in order to achieve efficiency and effectiveness (Moynihan, 2008). According to their study, managerial involvement has little effect on performance information use, but other factors, such as learning routines, the motivational nature of the task, and leadership commitment are positively associated with performance information use. Due to limited data, however, Moynihan and Lavertu (2012) could not examine all indicators together.

To update Moynihan and Lavertu's (2012) study, the present study uses recent data with advanced statistical methods. Based on previous research, this study mainly examines the relationship between performance information use and managers' involvement in goals, awareness of these goals, and accountability, based not only on the content of the information in use, but also on how the information was used. This study utilizes specific categories within passive and purposeful use, following Moynihan and Lavertu's (2012) study. For analyzing a manger's involvement and awareness of goals, this study employs the proximity concept, commonly used in social science fields.

\section{Manager's proximity}

Public managers could perceive a situation differently because of their different experiences and diverse individual needs (Schermerhorn et al., 2008). Therefore, 'the quality or accuracy of a person's perceptions has a major impact on his or her responses to a given situation. Perceptual responses are also likely to vary between managers and subordinates' (Schermerhorn et al., 2008, p. 32). This is the dynamic described in Miles' Law: 'where you stand depends on where you sit'. For example, Buchanan (1974) argues that if managers, especially those who are fully involved in a program, have been engaged in performance assessment activities, they are more likely to commit to performance-related activities. On the other hand, managers who are familiar with performance activities are more likely to access performance information.

A manager's level of involvement or commitment could be examined by proximity. The concept of proximity consists of both objective and subjective proximity (Cole $e t$ al., 2013; Wilson et al., 2008). Objective proximity can be neutrally measured or calculated, while subjective proximity is defined as actors' perceptions of closeness or distance from persons or systems (Wilson et al., 2008). Whether objective or subjective, a high level of proximity increases the motivation or willingness to act (Balcetis and Dunning, 2010). From this perspective, a manager's proximity effects include direct involvement in setting targets and performance metrics, and this also comprises cognitive efforts by managers to recognize information and their feelings about outcomes. 
Managers who have a high proximity to the performance system - that is, managers who are more involved in performance measures for a specific program or program evaluations-related activities - are more willing to obtain beneficial information to improve performance to achieve good results the following year. Furthermore, managers who have a high level of subjective proximity to a performance system - particularly, those who are aware of the specific programs featuring performance-related activities that enable them to improve their skills and knowledge - gain access to valuable information. If managers pay more attention to the use of performance data in decision-making, they are more willing to use performance information.

Moynihan and Ingraham (2004) argue that 'the greater the accessibility and detail of information, the greater the likelihood of information use' (p. 437) For example, a manager's degree of involvement in strategic goals and objectives enables their use of performance information in setting performance indicators. Accordingly, this study examines the level of managerial involvement in a system, namely proximity to it. Therefore, this study anticipates that if managers are involved in performance management, including goal setting, allocating resources, and performance measurement, they will also tend to be actively involved in performance information use. From this perspective, we can expect that if managers have a high level of proximity to the performance system, specifically managers who are familiar with or involved in performance-related activities, they will tend to be actively involved in performance information use, which achieves the goal of the GPRAMA.

H1: Actual proximity will have a positive effect on performance information use.

H2: Perceived proximity will have a positive effect on performance information use.

\section{Manager's accountability}

Public managers have increasingly faced complex tasks, and they involve setting policy priorities, developing strategies, communicating ideas with their members, and allocating resources, encouraging the achievement of program goals. As such, a public leader's role is highly concerned with how they demonstrate skills and manage resources to enhance organizational changes and capacities (Yukl, 2006). Furthermore, these complex tasks are gradually accompanied by complex accountability (Ossege, 2012). The emphasis of accountability of NPM reforms changed from hierarchical and legal accountability for inputs and processes (Heinrich, 2002) to accountability for outcomes with increased flexibility in decision making (Page, 2006). In other words, accountability concerns the relations between managers and subordinates in a hierarchy structure (Mulgan, 2003). Lately, however, managers have gained more access to information according to recently enacted laws because they are involved in the building of strategic goals with high levels of decision-making authority based on environmental complexity and flexibility. Thus, managers are more likely to aim to 'achiev[e] desirable societal outcomes' (Bovens et al., 2008, p. 232). Usilaner and 
Soniat (1980) and Huberman (1983) also note that managers with a high level of accountability tend to utilize this information in their decision-making.

Thus, managing performance is sometimes labeled as an accountability system (Radin, 2006) because leaders in public organizations are required to give an account of their performance data (Van de Walle and Cornelissen, 2014). Steccolini (2004) describes accountability systems in the public sector: 'the last decades have generally witnessed shifts in the idea of accountability diffused in the public sector; for example, from a concern for fiduciary, or probity and process accountability, focused on compliance, to an emphasis on managerial or performance and programme accountability, focused on effectiveness and efficiency, outcomes and outputs' (p. 331). From this perspective, Thamhain (2004) argues that leaders' accountability is the key criterion for carrying out an effective project that motivates members to accomplish their goals and objectives. Furthermore, accountability can be achieved by providing high-quality information to encourage good decision-making and to communicate desirable abilities to stakeholders (Ingraham and Donahue, 2000; Macintosh, 1994).

The GPRA granted more discretion to agencies concerning selecting their strategic goals and measures than did the PART evaluation (Kroll, 2015). Empirical studies have examined that a public manager with a high level of discretion is more likely to have a high level of accountability. Moynihan and Pandey (2010, p. 852) note that employees have discretion about 'whether and the degree to which they engage in it', and managers have different types of discretion, such as discretion over HR, over financial systems, and over aligning their mission with their actions (Moynihan, 2008). Therefore, these managers have a different understanding of what performance data means and what actions can be drawn from this information. In other words, managers employ a different level of performance information use based on their understanding and discretion. Kroll (2015) argues that public managers use performance information when they have the discretion to choose and change indicators, taking on ownership of data. On the other hand, several scholars have become alerted to managers' high levels of accountability and discretion. Managers who exercise great discretion in selecting their measures of performance data are especially likely, relative to other actors, to use performance data for advocacy purposes (Moynihan and Andrews, 2010) because GPRA posed challenges when it came to achieving agreement on the definitions and interpretations of goals, measures, and data between the OMB and federal agencies (Kroll, 2015).

Empirical studies have also explored how a leader's role is associated with performance information use (Moynihan and Ingraham, 2004; Dull, 2009; Moynihan et al., 2012; Melkers and Willoughby, 2005; Andrew and Moynihan, 2002; Askim et al., 2008). For example, leadership combined with dedicated support for performance processes and credible commitment influences performance reforms and performance information use (Moynihan et al., 2011). Dull (2009) and Moynihan and Ingraham (2004) have also found leaders' commitment and accountability to be a critical factor in performance information across various management functions. Kroll (2013) has also found 
that managers' responsibility for the results has been associated with performance information use. Thus, a manager's accountability has effects on how they employ high-quality performance information for correct decision-making (Ingraham and Donahue 2000; Macintosh 1994).

H3: Accountability will have a positive effect on performance information use.

\section{Organizational behaviors}

Many studies have found that organizations have in recent years devoted a great deal of effort, and considerable time and energy, to enhancing the accuracy of the measurement of management strategies that could lead to the improvement of performance information use (de Lancer Julnes and Holzer, 2001; Behn, 2002; de Lancer Julnes, 2008). Moynihan and Pandey (2010) argue that organizational behavior factors, including organizational cultures and external influences, play a key role in use of performance information. In addition, Taylor (2014) contends that 'the effects of performance information on organizational performance depend on the organization's culture' (p. 9), and that 'organizational culture was the dominant antecedent of performance information use' (p. 10). Organizational culture includes organizational efforts to achieve a high status of measurement features, such as quality of data, meaningful measures, and consistency definitions.

The key to increasing the use of performance information is acquiring and providing high-quality evidence for it, and towards this end organizational efforts to increase the quality of performance data as an organizational factor have attracted increased attention in recent years. Performance data based on sophisticated measurements can be used as performance information because decision makers can trust and use performance information if it has high validity and accuracy (Van Dooren, 2011). Therefore, performance measurement and measurability have come to play a key role in using performance information based on accountability schemes (Van Dooren et al., 2010). Increasing the data's credibility helps decision makers make better decisions and more effectively allocate resources. Ammons (1995) also argues that 'more sophisticated measurement systems will undergird management processes, better inform resource allocation decisions, enhance legislative oversight, and increase accountability' (p. 37). Therefore, it is highly significant to collect meaningful measures and high-quality data for improving the use of performance information, a crucial resource for decision makers. Consequently, performance measurement efforts include investing in the resources needed to ensure the sufficient quality of performance data, providing meaningful measures based on experience with such programs, and having clear goal definitions to measure performance. From this perspective, investing resources to increase the quality of performance data supports and fosters the use of performance information.

One of the organizational behavior factors conceptualized by Moynihan and Pandey (2010) is external stakeholders. According to Yang and Hsieh (2007), stakeholders' 
participation is positively associated with the effectiveness of performance measures. In addition, certain professional organizations, such as the Governmental Accounting Standards Board, the National Academy of Public Administration, the National Conference of State Legislatures, Congress, the OMB, and auditor communities that have helped to establish norms in public institutions, have a positive influence on performance management and provide guidance and recommendations (Moynihan and Pandey, 2010; Moynihan and Lavertu, 2012). Additionally, de Lancer Julnes and Holzer (2001) also found that support from external interest groups for performance management also fostered performance information use. Based on these findings, this study includes attention from the OMB, congressional committees, and the auditor community as external influences.

Summarizing, this study analyses the effects of managers' proximity and accountability on performance information use. On the independent, a distinction is made between objective and subjective proximity. On the dependent, this study differentiates between passive and purposeful use of performance information. Moreover, this study controls for organizational factors including external influence.

\section{Data and methods}

This study utilizes the data from a survey of federal employees administered by the U.S. Government Accountability Office (GAO) in 2013 and 2017. The GAO points out that agencies report performance measures to assess progress against goals in their strategic plans (GAO, 1992). The GAO survey uses stratified sampling of mid-level and upper-level managers and supervisors by agency and distinguishes whether the manager or supervisor was a member of the Senior Executive Service (SES) or was in one of the 'non-SES' agencies among the 24 affected by the Chief Financial Officers (CFO) Act of 1990. In 2013, the average response rate across all agencies hovered around 69\%, among 4,391 managers who responded from a population of approximately 148,300 mid-level and upper-level civilian managers selected from those working in executive agencies and government-wide organizations (GAO, 2014). Meanwhile, the response observation rate across agencies was around $67 \%, 3,114$ managers, from a stratified random sample of 4,395 managers chosen from a population of about 153,779 mid-level and upper-level civilian managers and supervisors from the 24 executive branch agencies in 2017 (GAO, 2017). This study totaled 2,762 managers in 2013 and 2,718 managers in 2017, after data cleaning.

Table 1 provides the full measurement details, including descriptive statistics. The dependent variable of this study is performance information use; therefore, one question asked respondents to measure the level of each type of performance information use. The answer was re-coded as 1 if respondents indicated 'no extent' or 'not applicable'; 2 , if respondents agreed with 'to a small extent'; 3 , if respondents used performance information 'to a moderate extent'; 4 , if respondents indicated 'to a great extent'; and 5 , if respondents indicated 'to a very great extent.' 


\section{MANAGER'S PROXIMITY}

Involvement in PM

Involvement in CAP Goals

Involvement in Priority Goals

Awareness of CAP Goals

Awareness of Priority Goals

Awareness of PR

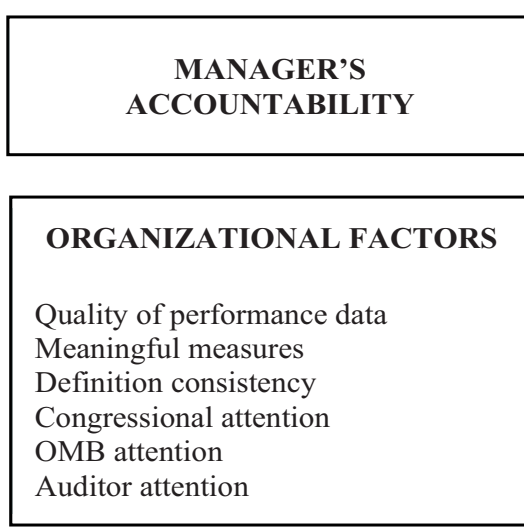

INFORMATION USE

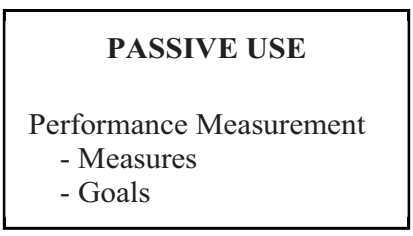

PURPOSEFUL USE

Program Management

- Processes

- Priorities

- Resources

Employee Management

- Expectations

- Rewards

Problem Solving

- Problem Identification

- Correction

*Note: PM denotes performance measures, CAP means cross-agency priority, and PR denotes performance review.

Figure 1: Research model

For managers' objective proximity - the primary independent variable - there are three variables, 'involvement in performance measures', 'involvement of CAP (Cross-Agency Priority) goals', and 'involvement of priority goals.' The first variable is a binary variable; if respondents indicated any sort of involvement, their responses were coded as 1 ; otherwise, they were coded as 0 . For managers' subjective proximity - the secondary independent variable - there are three variables: 'awareness of CAP (Cross-Agency Priority) goals', 'awareness of priority goals', and 'awareness of PR (Performance Review report)'. These three independent variables were re-coded as 1 if respondents indicated 'no extent' or 'not applicable'; 2 , if respondents agreed with 'to a small extent'; 3 , if respondents used performance information 'to a moderate extent'; 4, if respondents indicated 'to a great extent'; and 5, if respondents indicated 'to a very great extent.' This study also includes manager's accountability with two variables, each ranging 1 to 5 . Control variables are measurement related issues - quality of data, meaningful measures, and definition consistency. Control variables include stakeholders' attention - Congressional, OMB, and Auditor attention - to account for organizational factors, following Moynihan and Lavertu's study (2012). Moreover, this study contains only SES status, and demographic variables (e.g., race, income, and education level) were not included on the basis of 4 C.F.R. $\S 81.6(1)$, which states that GAO will not release records. 


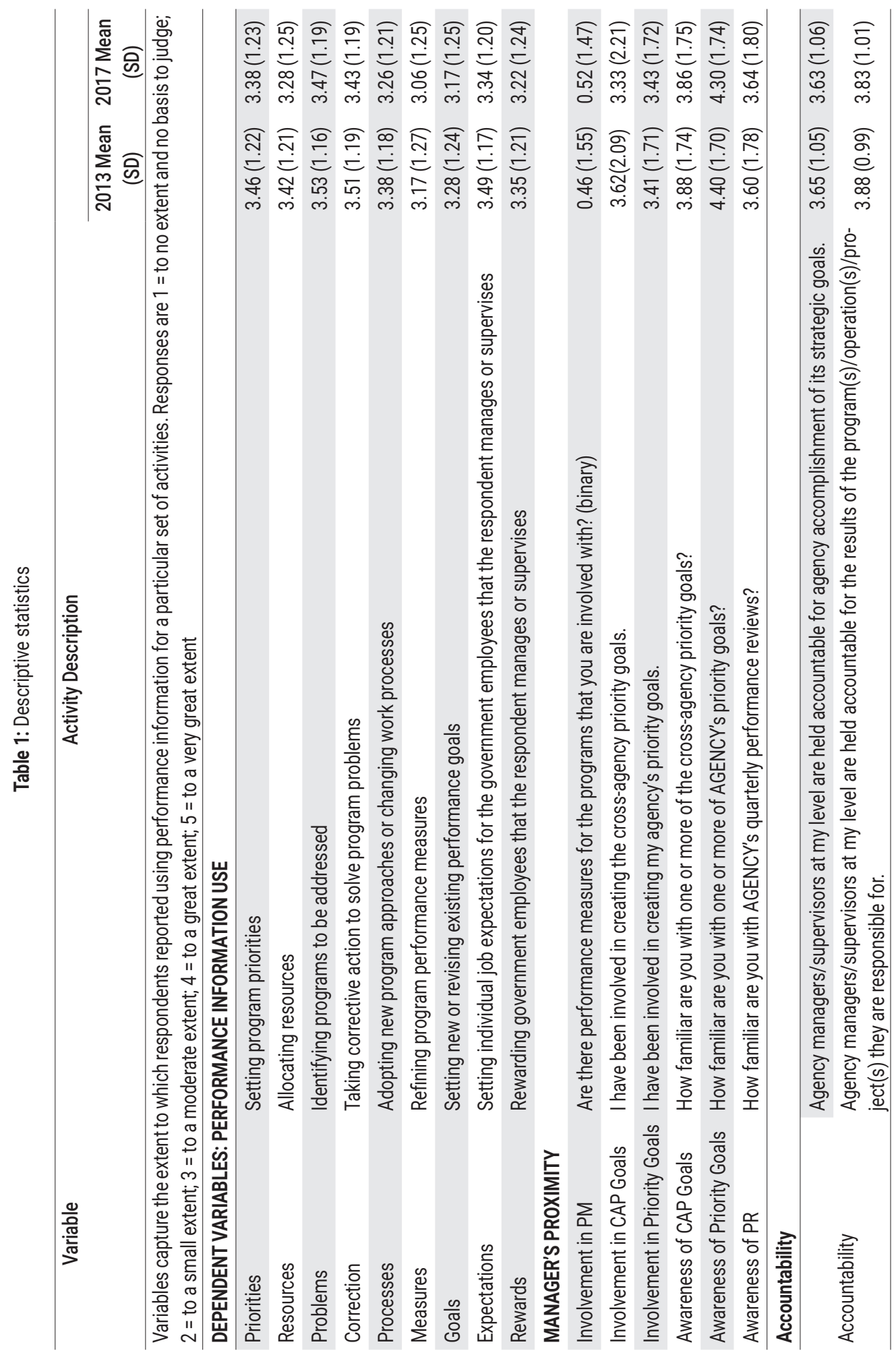




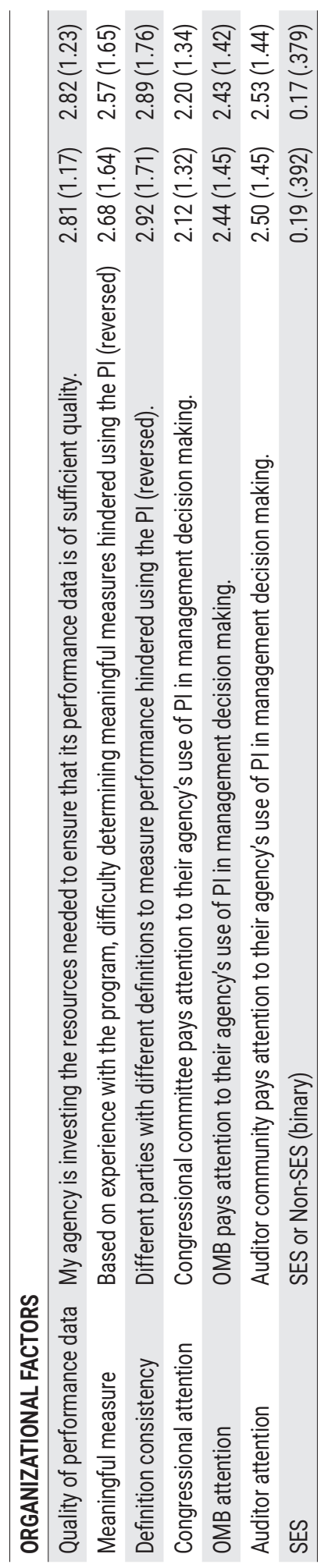




\section{Results}

This study employs the Stereotype Logistic Model (SLM) to estimate ordinal mathematics proficiency, such as the directions and magnitudes of the relationship among factors (Anderson, 1984; Liu, 2014). This study uses survey data for the dependent variables, different types of information use, which are on a 5-point ordinal scale, ranging from 1 (no extent) to 5 (to a very great extent). There are two reasons for using SLM. First, SLM was introduced by Anderson (1984) for solving the restrictive assumption of parallel regression in the ordered logit model (Long, 2014). Many researchers often use ordinary least squares, assuming that ordinal dependent variables can be considered as the interval level variables (Long, 1997). They use ordered logit or probit regression models due to their ordinal scale variables, as these are supposed to uphold the parallel regression assumption. However, if the parallel regression assumption does not hold, proportional odds models give incorrect results (Erkan and Yildiz, 2014). For example, Liu (2014) compares two statistical methods - the proportional odds model (PO) and SLM - and finds that SLM is a better option when the assumption is untenable. This study conducts a Brant test that indicates the parallel regression assumption was violated when we employed ordered logit and probit models using the data. The parallel regression assumption does not hold, and the SLM offers a better fit. Second, since our study is nonlinear, standard generalized linear model methods do not fit the data. The SLM, which employs maximum likelihood estimation, is used with categorical dependent variables that include a subjective ranking scheme. Despite the non-linearity and lack of identifiability of the parameters, the SLM allows for the determination of a particular ordinal level for a given observation.

Table 2 provides the SLM results for the model based on robust standard errors. The Wald $\chi^{2}$ statistics of all models indicate that the models fit well. The results show that the three variables of objective proximity to the performance system - involvement in performance measurement, CAP goals, and priority goals - are used, and manager's involvement in performance measurement is positively associated with all types of performance information use. Yet, involvement in CAP goals was shown to be negatively connected with passive use of performance information. Involvement of priority goals was, conversely, positively linked with the passive use of performance information. This result simply reiterates that a manager's objective proximity to performance-related activities is a significant predictor of performance information use, partially supporting H1. On the other hand, this does not mean that awareness of performance-related activities has been directly connected with increased performance information. Thus, this study includes subjective proximity to the performance system. Regarding a manager's subjective proximity, awareness of priority goals and performance review reports have positive effects on most types of performance information use. Awareness of priority goals is positively associated with purposeful use of performance information, and it does not affect passive use, partially supporting $\mathrm{H} 2$. 
In Table 2, the second independent variable - accountability - is shown to be highly related to performance information use, supporting H3. Managers, who possess a high level of decision-making authority with which to accomplish their goals, are more likely to use performance information, both passively and purposefully. If managers are held accountable for the accomplishment of goals, they are favorable towards using performance information. In other words, having top leaders with a strong commitment to achieving results is positively associated with performance information use. These results support Dull's (2009) findings, and GAO (2000, 2008, 2014) reports that a leader's commitment is positively correlated with performance information use.

Many federal managers are willing to use performance data (Moynihan and Pandey, 2010) and build an organizational culture that is supportive of using performance information (Broadnax and Conway, 2001; Franklin, 2000). Measurement as an aspect of organizational culture matters. Investing resources for quality performance data ensures that an organization's performance data increases to a sufficient quality, fostering performance information use. If managers consider their programs to have meaningful measures, they are willing to use performance information. This finding confirms Moynihan and Lavertu's (2012) study.

In addition, based on the main requirements of the GPRA reforms, federal agencies consult with $\mathrm{OMB}$, Congress, and other stakeholders to develop the agency's mission statement (Ho, 2007). On the other hand, this study has found that the main parts of GPRA reforms have weak effects on performance information use. Rather than stakeholder attention, technical efforts for acquiring reliable and valid performance data and setting intended goals with meaningful measures are strongly associated with performance information use. This supports Posner and Fantone's (2007) study that external stakeholders, such as Congress, have not been concerned with the development of performance activity, which controverts the legislative intent of GPRA, that is, that agencies' performance goals should be consulted by Congress and other stakeholders (Ho, 2007). This effect could lead to the use of performance information.

The results from the output could be simply summarized. First, involvement in priority goals and measurements has positive effects on performance information use while involvement in CAP goals is negatively related to the passive use and employee management of purposeful use. Second, involvement in priority goals has a positive effect on passive use, while awareness of priority goals is positively related to the purposeful use of performance information. This result suggests that some types of proximity to a performance system encourage performance information use, and other types of proximity discourage or have no effects on performance information use. Third, manager's accountability plays a key factor in use of performance information use regardless of the type of performance information. 


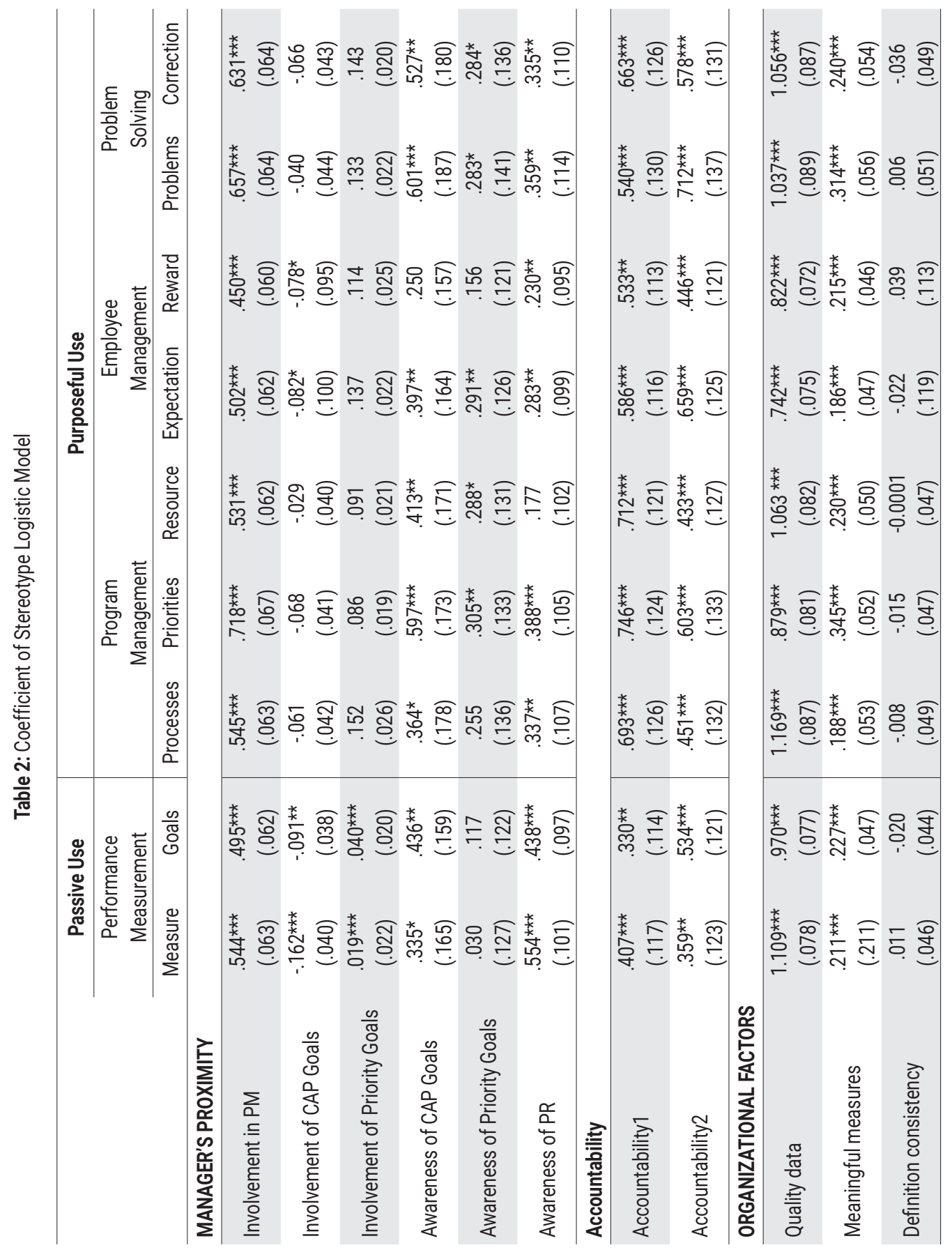




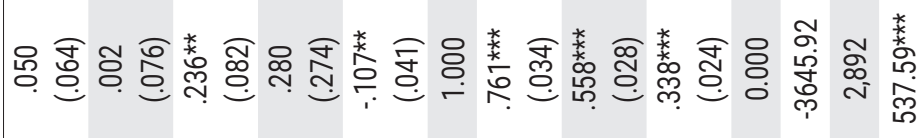

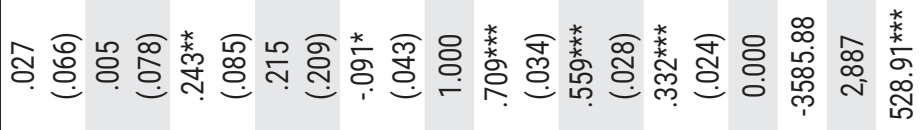

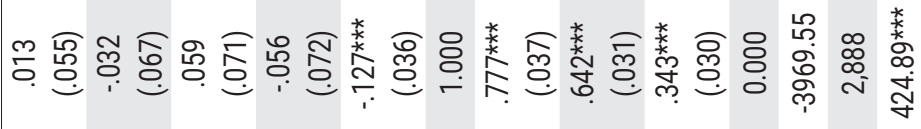

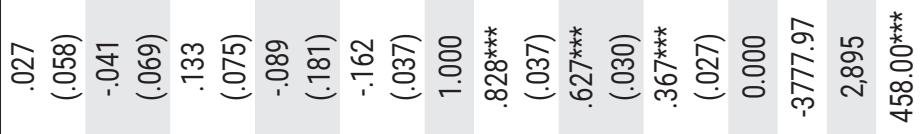

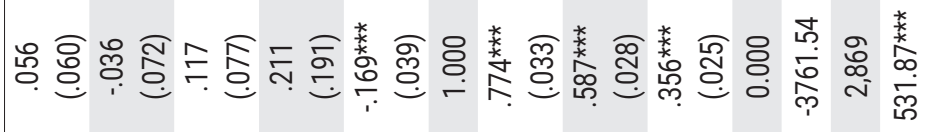

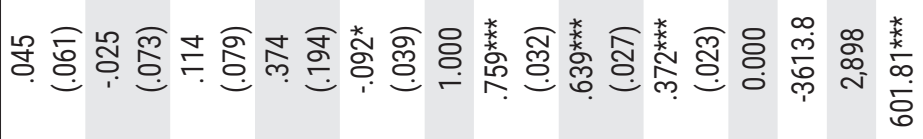

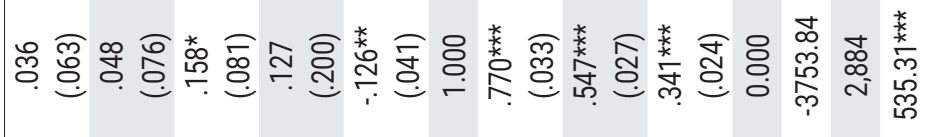

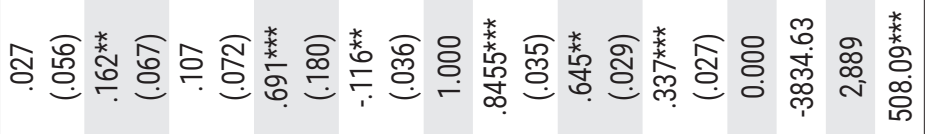

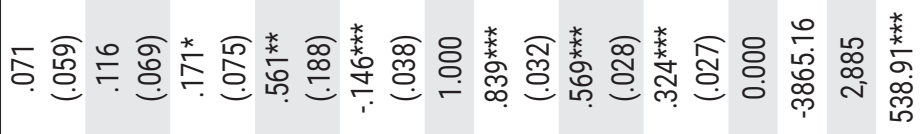

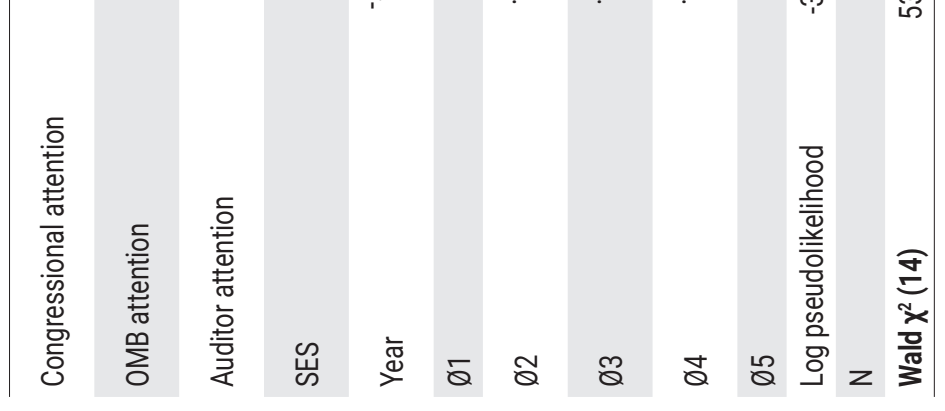




\section{Conclusion}

The topics of performance evaluation and performance measurement issues have been frequently examined by many leading scholars (Bouckaert and Halligan, 2008; Hatry, 1999; Talbot 2010; Moynihan, 2008; Van Dooren et al., 2010), but few studies exist that address performance information use (Moynihan, 2008; Van Dooren and Van de Walle, 2008). This article, therefore, argues for examining performance information use as a key variable alongside various factors, such as proximity to the performance system, accountability, and organizational factors.

The results have confirmed the positive effects of manager proximity, such as managerial involvement in performance measurement, awareness of CAP goals, and awareness of priority goals. Among these proximity effects, objective proximity positively affects the passive use of performance information that focuses simply on complying with norms to report the requirements (Moynihan, 2009). This result simply follows the traditional approach, in which public officials use performance information to make decisions with regards to repeated actions in the government, such as setting slightly modified goals (Hatry, 1999).

Interestingly, on the other hand, a manager's involvement in CAP goals has negative effects on passive and purposeful use, while awareness has positive effects. This might be explained by examination of the different characteristics of goals. CAP goals are used as tools by managers to improve their progression through multiple agencies based on active collaboration. The GPRA Modernization Act of 2010 requires agencies to set CAP goals that cover a limited number of presidential priority areas, where several agencies have increased coordination on outcome-focused goals. CAP goals are required to be set every four years and managed by at least two goal leaders from the Executive Office of the President and key agencies who will execute the process (Section 200.9). All CAP goals have a governance team (e.g., working groups, inter-agency policy committees, $\mathrm{OMB}$, and councils) to achieve these goals, review performance, and develop an action plan (Section 200.9). CAP goal leaders review goal performance together through diagnosing problems, identifying opportunities, and deciding the next steps to increase performance. This could be helpful in diagnosing performance problems, but it is also difficult to ensure alignment between goals and activities, and to identify strategies for improvement based on complex problems through clear communication among diverse members and agencies who have different approaches to these goals. On the other hand, a manager's commitment to CAP goals might be lower than another agency's goals. This issue is associated with the goal setting theory. For example, managers have a high level of commitment to priority goals and agency-assigned goals to improve performance, which is directly related to agency performance. Since diverse agencies share CAP goals, managers are merely motivated to achieve such goals. Thus, managers who are involved in CAP goals may be reluctant to use performance information because of the complexity of relationships among goal leaders and the different situations related to goal progression among agencies that need distinctive strategies. 
According to the results of the current study, a manager's accountability is an exceedingly substantial component in passive and purposeful use. A public manager's accountability stimulates performance information because it is considered the 'raw material for the account' (Stewart, 1984, p. 26). Agencies provide more information on performance such as efficiency and effectiveness (Hyndman and Anderson, 1997), at the same time, agencies collect performance information as a matter of routine, and it is embedded in their management processes. A manager's accountability is mainly accountable to the outcomes of their decisions (Stewart, 1984). Thus, they are more likely to employ performance information as a tool for achieving results and outcomes.

Investment resources related to the quality of performance data and meaningful measures are positively associated with performance information use regardless of the type of performance information, while definitional consistency has no influence on performance information uses. Moreover, OMB and auditor attention have effects on only certain types of performance information use; nonetheless, congressional attention has no effect on performance information use. This result shows similar findings from the previous studies, which showed that politicians and board members did not use performance information to control service delivers (Day and Klein, 1987). Thomas (1998) has also found that while Australia and New Zealand have published sophisticated performance information, parliamentarians have seldom used it. In U.S. government agencies, the GPRA Modernization Act of 2010 requires that agencies consult with $\mathrm{OMB}$ and Congress in the designation of CAP goals and agency priority goals. Congress is particularly bound by term limits and their attention focuses mainly on politically sensitive information rather than performance information for solving program goals and revising performance goals. Thus, performance information can be hardly used as an interactive dialogue between external stakeholders and agencies.

This study makes several contributions to this field. First, this study employs different types of goals (e.g., priority goals and CAP goals). Many studies have examined agency goals without considering goal type This study contributes the discovery that examining different types of agency goals is significantly important and that they produce different effects on performance information use. Managers are motivated by performance information use when they become involved in or participate in priority goals, and they are less likely to use performance information when they are involved in setting CAP goals that are shared among agencies. Second, this study utilizes Miles' Law and categorizes manager's proximity into involvement (objective) in goals and awareness (subjective) of goals for analyzing the use of performance information. This study has found that objective proximity has a significant impact on the passive use of performance information while subjective proximity has a positive influence on performance information use regardless of the type of performance information. This may contribute to performance management studies by identifying managerial proximity effects that only emerge in public administration. 
This study contains several limitations, and further investigation is needed. First, when a study uses survey data, many scholars argue that common measurement issues, such as common source bias and survey method issues, yield biased and unreliable results because perceptions are simply very subjective judgments or estimations. Specifically, common measurement leads to biased estimates of the covariance or estimates of correlation or regression coefficients (Favero and Bullock, 2015). Thus, future research needs to include independent data sources. Second, to preserve anonymity, this study could not include individual characteristics, such as the number of years a respondent reported serving as a supervisor at their agency. Most individuals' data are not identified by their agencies; therefore, further studies must examine agency-fixed effects to allow for a model that explains the variation in each agency's task environment.

\section{References:}

1. Ammons, D.N., 'Overcoming the Inadequacies of Performance Measurement in Local Government: The Case of Libraries and Leisure Services', 1995, Public Administration Review, vol. 55, no. 1, pp. 37-47.

2. Anderson, J.A., 'Regression and Ordered Categorical Models', 1984, fournal of the Royal Statistics Society, vol. 46, no. 1, pp. 1-22.

3. Askim, J., 'The Demand Side of Performance Measurement: Explaining Councillors' Utilization of Performance Information in Policymaking', 2009, International Public Management fournal, vol. 12, no. 1, pp. 24-47.

4. Askim, J., Johnsen, A. and Christophersen, K., 'Factors Behind Organizational Learning from Benchmarking: Experiences from Norwegian Municipal Benchmarking Networks', 2008, Journal of Public Administration Research and Theory, vol. 18, no. 2, pp. 297-320.

5. Balcetis, E. and Dunning, D., 'Wishful Seeing: More Desired Objects Are Seen as Closer', 2010, Psychological Science, vol. 21, no. 1, pp. 147-152.

6. Behn, R.D., 'The Psychological Barriers to Performance Management: Or Why Isn't Everyone Jumping on the Performance-Management Bandwagon?', 2002, Public Performance \& Management Review, vol. 26, no. 1, pp. 5-25.

7. Behn, R.D., 'Why Measure Performance? Different Purposes Require Different Measures', 2003, Public Administration Review, vol. 63, no. 5, pp. 586-606.

8. Bouckaert, G. and Halligan, J., Managing Performance: International Comparisons, London: Routledge, 2008.

9. Buchanan, B., 'Government Managers, Business Executives, and Organizational Commitment', 1974, Public Administration Review, vol. 34, no. 4, pp. 339-347.

10. Bovens, M., Schillemans, T. and Hart, P.T., 'Does Public Accountability Work? An Assessment Tool', 2008, Public Administration, vol. 86, no. 1, pp. 225-242.

11. Broadnax, W.D. and Conway, K.J., 'The Social Security Administration and Performance Management', in Forsythe, D.W. (ed.), Quicker, Better, Cheaper, Albany, N.Y.: Rockefeller Institute Press, 2001, pp. 143-176.

12. Cole, S., Balcetis, E. and Dunning, D., 'Affective Signals of Threat Increase Perceived Proximity’, 2013, Psychological Science, vol. 24, no. 1, pp. 34-40. 
13. Day, P. and Klein, R., Accountabilities: Five Public Services, London: Tavistock, 1987.

14. De Lancer Julnes, P., 'Performance Measurement beyond Instrumental Use', in Van Dooren, W. and Van de Walle, S. (eds.), Performance Information in the Public Sector: How It Is Used, Basingstoke, UK: Palgrave Macmillan, 2008, pp. 58-71.

15. De Lancer Julnes, P. and Holzer, M., 'Promoting the Utilization of Performance Measures in Public Organizations: An Empirical Study of Factors Affecting Adoption and Implementation', 2001, Public Administration Review, vol. 61, no. 6, pp. 693-708.

16. Dull, M., 'Results-Model Reform Leadership: Questions of Credible Commitment', 2009, Journal of Public Administration Research and Theory, vol. 19, no. 2, pp. 255-284.

17. Erkan, A. and Yildiz, Z., 'Parallel Lines Assumption in Ordinal Logistic Regression and Analysis Approaches', 2014, International Interdisciplinary Journal of Scientific Research, vol. 1, no. 33, pp. 8-23.

18. Favero, N. and Bullock, J.B., 'How (Not) to Solve the Problem: An Evaluation of Scholarly Responses to Common Source Bias', 2015, Journal of Public Administration Research and Theory, vol. 25, no. 1, pp. 285-308.

19. Franklin, A., 'An Examination of Bureaucratic Reaction to Institutional Controls', 2000, Public Performance \& Management Review, vol. 24, no. 1, pp. 8-21.

20. Government Accountability Office (GAO), 'Supplemental Material for GAO-17-775: 2017 Survey of Federal Managers on Organizational Performance and Management Issues', GAO-17-776SP, Washington, D.C., 2017, [Online] available at https://www.gao.gov/ products/gao-17-776sp, accessed on January 12, 2021.

21. Government Accountability Office (GAO), 'Managing for Results: Agencies' Trends in the Use of Performance Information to Make Decisions', GAO-14-747, Washington, D.C., 2014, [Online] available at https://www.gao.gov/assets/gao-14-747.pdf, accessed on January 12, 2021.

22. Government Accountability Office (GAO), 'GPRA Modernization Act Provides Opportunities to Help Address Fiscal, Performance, and Management Challenges', GAO-11-466T, Washington, D.C., 2011, [Online] available at https://www.gao.gov/assets/gao-11-466t. pdf, accessed on January 12, 2021.

23. Government Accountability Office (GAO), 'Managing for Results: Emerging Benefits from Selected Agencies' Use of Performance Agreements', GAO-01-115, Washington, D.C., 2000, [Online] available at https://www.gao.gov/assets/gao-01-115.pdf, accessed on January 12, 2021.

24. Government Accountability Office (GAO), 'Lessons Learned for the Next Administration on Using Performance Information to Improve Results', GAO-08-1026T, Washington, D.C., 2008, [Online] available at https://www.gao.gov/assets/gao-08-1026t.pdf, accessed on January 12, 2021.

25. Government Accountability Office (GAO), 'Performance Measurement: An Important Tool in Managing for Results', GAO-T-GGD-92-35, Washington, D.C., 1992, [Online] available at https://www.gao.gov/assets/t-ggd-92-35.pdf, accessed on January 12, 2021.

26. Hatry, H., Performance Measurement: Getting Results, Washington, D.C.: Urban Institute Press, 1999.

27. Heinrich, C.J., 'Outcomes-based Performance Management in the Public Sector: Implications for Government Accountability and Effectiveness', 2002, Public Administration Review, vol. 62 , no. 6, pp. $712-725$. 
28. Ho, A., 'GPRA after a Decade: Lessons from the Government Performance and Results Act and Related Federal Reforms: Introduction', 2007, Public Performance \& Management Review, vol. 30, no. 3, pp. 307-311.

29. House, R.J., Hanges, P.J., Javidan, M., Dorfman, P.W. and Gupta, V., Culture, Leadership, and Organizations: The GLOBE Study of 62 Societies, Thousand Oaks, C.A.: Sage Publications, 2004.

30. Houston, D.J., 'Walking the Walk' of Public Service Motivation: Public Employees and Charitable Gifts of Time, Blood, and Money', 2006, fournal of Public Administration Research and Theory, vol. 16, no. 1, pp. 67-86.

31. Huberman, M., 'Recipes for Busy Kitchens: A Situational Analysis of Routine Knowledge Use in Schools', 1983, Knowledge, vol. 4, no. 4, pp. 478-510.

32. Hyndman, N.S. and Anderson, R., 'A Study of the Use of Targets in the Planning Documents of Executive Agencies', 1997, Financial Accountability \& Management, vol. 13, no. 2, pp. 139-163.

33. Ingraham, P.W. and Donahue, A.E., 'Dissecting the Black Box Revisited: Characterizing Government Management Capacity', in Heinrich, C.J. and Lynn Jr., L.E. (eds.), Government and Performance: New Perspectives, Washington, D.C.: Georgetown University Press, 2000.

34. Jennings Jr., E.T. and Haist, M.P., 'Putting Performance Measurement in Context', in Ingraham, P.W. and Lynn Jr., L.E. (eds.), The Art of Governance: Analyzing Management and Administration, Washington, D.C.: Georgetown University Press, 2004, pp. 173-194.

35. Joyce, P.G., 'Linking Performance and Budgeting: Opportunities in the Federal Budgeting Process', Washington, DC: IBM Center for the Business of Government, 2003, [Online] available at https://blog-pfm.imf.org/pfmblog/files/joyce_report1.pdf, accessed on January $25,2021$.

36. Kluvers, R. and Tippett, J., 'The NPM: The Trojan Horse in Accountability', 2012, The International fournal in Business and Management, vol. 7, no. 3, pp. 3-9.

37. Kroll, A., 'The Other Type of Performance Information: Nonroutine Feedback, Its Relevance and Use', 2013, Public Administration Review, vol. 73, no. 2, pp. 265-276.

38. Kroll, A., 'Explaining the Use of Performance Information by Public Managers: A Plannedbehavior Approach', 2015, American Review of Public Administration, vol. 45, no. 2, pp. 201-215.

39. Kroll, A. and Vogel, D., 'The PSM-Leadership Fit: A Model of Performance Information Use', 2014 Public Administration, vol. 92, no. 4, pp. 974-991.

40. Lavertu, S. and Moynihan, D.P., 'Agency Political Ideology and Reform Implementation: Performance Management in the Bush Administration', 2012, fournal of Public Administration Research and Theory, vol. 23, no. 3, pp. 521-549.

41. Long, J.S., Regression Models for Categorical and Limited Dependent Variables, Thousand Oaks, C.A.: Sage Publications, 1997.

42. Long, J.S., 'Regression Models for Nominal and Ordinal Outcomes', in Best, H. and Wolf, C., The SAGE Handbook of Regression Analysis and Causal Inference, Thousand Oaks, C.A.: Sage Publications, 2014.

43. Liu, X., 'Fitting Stereotype Logistic Regression Models for Ordinal Response Variables in Educational Research', 2014, Journal of Modern Applied Statistical Methods, vol. 13, no. 2, pp. 528-545. 
44. Macintosh, N.B., Management Accounting and Control Systems: An Organizational and Behavioral Approach, Chichester, UK: John Wiley \& Sons, 1994.

45. Majone, G., Evidence, Argument, and Persuasion in the Policy Process, New Haven, C.T.: Yale University Press, 1989.

46. Mayne, J., 'Accountability for Program Performance: A Key to Effective Performance Monitoring and Reporting', in Mayne, J. and Zapico-Goni, E. (eds.), Monitoring Performance in the Public Sector: Future Directions from International Experience, New Brunswick, NJ: Transaction Publishers, 1997, pp. 157-174.

47. Melkers, J. and Willoughby, K., 'Models of Performance-measurement Use in Local Governments: Understanding Budgeting, Communication, and Lasting Effects', 2005, Public Administration Review, vol. 65, no. 2, pp. 180-190.

48. Moynihan, D.P., The Dynamics of Performance Management: Constructing Information and Reform, Washington, D.C.: Georgetown University Press, 2008.

49. Moynihan, D.P., 'Through a Glass Darkly: Understanding the Effects of Performance Regimes', 2009, Public Performance \& Management Review, vol. 32, no. 4, pp. 592-603.

50. Moynihan, D.P. and Andrews, M., 'Budgets and Financial Management', in Walker, R.M., Boyne, G.A. and Brewer, G.A. (eds.), Public Management and Performance: Research Directions, Cambridge: Cambridge University Press, 2010, pp. 60-88.

51. Moynihan, D.P. and Ingraham, P.W., 'Integrative Leadership in the Public Sector: A Model of Performance Information Use', 2004, Administration \& Society, vol. 36, no. 4, pp. 427453.

52. Moynihan, D.P. and Lavertu, S., 'Does Involvement in Performance Management Routines Encourage Performance Information Use? Evaluating GPRA and PART', 2012, Public Administration Review, vol. 72, no. 4, pp. 592-602.

53. Moynihan, D.P. and Pandey, S.K., 'The Big Question for Performance Management: Why Do Managers Use Performance Information?', 2010, fournal of Public Administration Research and Theory, vol. 20, no. 4, pp. 849-866.

54. Moynihan, D.P., Pandey, S.K and Wright, B.E., 'Prosocial Values and Performance Management Theory: Linking Perceived Social Impact and Performance Information Use', 2012, Governance, vol. 25, no. 3, pp. 463-483.

55. Moynihan, D.P., Pandey, S.K. and Wright, B.E., 'Setting the Table: How Transformational Leadership Fosters Performance Information Use', 2012, fournal of Public Administration Research and Theory, vol. 22, no. 1, pp. 143-164.

56. Mulgan, R., Holding Power to Account: Accountability in Modern Democracies, Springer, 2003.

57. Nahavandi, A., The Art and Science of Leadership, Canada: Pearson Education, 2011.

58. Ossege, C., 'Accountability - Are We Better Off Without It? An Empirical Study on the Effects of Accountability on Public Managers' Work Behaviour', 2012, Public Management Review, vol. 14, no. 5, pp. 585-607.

59. Page, S., 'The Web of Managerial Accountability', 2006, Administration and Society, vol. 38, no. 2, pp. 166-197.

60. Pandey, S.K. and Stazyk, E.C., 'Antecedents and Correlates of Public Service Motivation', in Perry, J.L. and Hondeghem, H. (eds.), Motivation in Public Management: The Call of Public Service, Oxford: Oxford University Press, 2008, pp. 101-117. 
61. Poister, T.H. and Streib, G., 'Performance Measurement in Municipal Government: Assessing the State of the Practice', 1999, Public Administration Review, vol. 59, no. 4, pp. 325-335.

62. Pollanen, R.M., 'Annual Performance Reporting as Accountability Mechanism in Local Government', 2014, International fournal of Business and Public Administration, vol. 11, no. 2, pp. 105-121.

63. Posner, P.L. and Fantone, D.M., 'Assessing Federal Program Performance: Observations on the US Office of Management and Budget's Program Assessment Rating Tool and Its Use in the Budget Process', 2007, Public Performance \& Management Review, vol. 30, no. 3, pp. 351-368.

64. Radin, B.A., Challenging the Performance Movement: Accountability, Complexity, and Democratic Values, Washington, D.C.: Georgetown University Press, 2006.

65. Schermerhorn, J., Hunt, J. and Osborn, R., Basic Organizational Behavior, $10^{\text {th }}$ edition, New York: John Wiley and Sons, 2008.

66. Steccolini, I., 'Is the Annual Report an Accountability Medium? An Empirical Investigation into Italian Local Government', 2004, Financial Accountability and Management, vol. 20, no. 3, pp. 327-350.

67. Stewart, J.D., 'The Role of Information in Public Accountability', in Hopwood, A. and Tomkins, C. (eds.), Issues in Public Sector Accounting, Oxford: Phillip Allan, 1984, pp. 13-34.

68. Talbot, C., 'Performance Management', in Ferlie, E., Lynn Jr., L.E. and Pollitt, C. (eds.), The Oxford Handbook on Public Management, Oxford: Oxford University Press, 2005, pp. 491-520.

69. Talbot, C., Theories of Performance: Organizational and Service Improvement in the Public Domain, Oxford: Oxford University Press, 2010.

70. Taylor, J., 'Organizational Culture and the Paradox of Performance Management', 2014, Public Performance \& Management Review, vol. 38, no. 1, pp. 7-22.

71. Thamhain, H.J., 'Linkages of Project Environment to Performance: Lessons for Team Leadership', 2004, International Journal of Project Management, vol. 22, no. 7, pp. 533-544.

72. Thomas, P., 'The Politics of Performance Measurement', 1998, Management, vol. 8, no. 2, pp. 17-19.

73. Usilaner, B. and Soniat, E., 'Productivity Measurement', in Washnis, G. (ed.), Productivity Improvement Handbook for State and Local Government, New York: John Wiley, 1980, pp. 91-114.

74. Van de Walle, S. and Cornelissen, F., 'Performance Reporting', in Bovens, M., Goodin, R.E. and Schillemans, T. (eds.), The Oxford Handbook on Public Accountability, Oxford: Oxford University Press, 2014, pp. 441-455

75. Van Dooren, W. and Van de Walle, S. (eds.), Performance Information in the Public Sector: How It Is Used, Houndmills, UK: Palgrave Macmillan, 2008.

76. Van Dooren, W., Bouckaert, G. and Halligan, J., Performance Management in the Public Sector, London: Routledge, 2010.

77. Van Dooren, W., 'Better Performance Management: Some Single- and Double-loop Strategies', 2011, Public Performance \& Management Review, vol. 34, no. 3, pp. 420-433.

78. Wilson, J.M., O’Leary, M.B., Metiu, A. and Jett, Q.R., 'Perceived Proximity in Virtual Work: Explaining the Paradox of Far-but-close', 2008, Organization Studies, vol. 29, no. 7, pp. 979-1002. 
79. Yang, K. and Hsieh, J.Y., 'Managerial Effectiveness of Government Performance Measurement: Testing a Middle Range Model', 2007, Public Administration Review, vol. 67, no. 5, pp. 861-879.

80. Yukl, G., Leadership in Organizations, ${ }^{\text {th }}$ edition, Upper Saddle, N.J.: Pearson Prentice Hall, 2006. 